\title{
ABORDAGENS DE TRADUÇÃo POÉTICA \\ PARA SAFO Fr. 31
}

\author{
Poetic translation approaches \\ for Sappho Fr. 31
}

C. Leonardo B. Antunes*

\begin{abstract}
RESUMO
Neste artigo, apresento algumas traduções poéticas e recriações do fragmento 31 de Safo (desde a versão de Catulo até minha própria recriação da recriação de Byron para os poemas de Safo e Catulo combinados) num empenho de analisar tanto o resultado prático de diversos posicionamentos distintos sobre métrica quanto a extensão da liberdade do tradutor em sua tarefa e da possibilidade de diálogo entre traduções e texto original.

Palavras-chave: Safo, tradução poética, fragmento 31 .
\end{abstract}

\begin{abstract}
In this paper I present several poetic translations and recreations of Sappho's fragment 31 (from Catullus' version to

* Universidade Federal do Rio Grande do Sul (UFRGS).
\end{abstract}


my own recreation of Byron's recreation of the poems of Sappho and Catullus) with an intent to analyze both the practical result of the various stances on meter as well as the extension of freedom the translator may enjoy in his task and the possibility of dialogue between different translations and the original text.

Keywords: Sappho, poetic translation, fragment 31.

O fragmento 31 de Safo (conhecido também como phainetai moi por conta de suas palavras iniciais) é talvez um dos mais belos exemplos de lirismo amoroso em toda a literatura ocidental. A prova disso (além da beleza do próprio poema, testemunha de si mesma) é a enorme quantidade de traduções e recriações que o texto recebeu ao longo dos séculos, começando ainda na antiguidade com Catulo (que imita o metro e o ritmo da estrofe sáfica perfeitamente em Latim no poema 51, ao fazer sua adaptação do phainetai moi). Outras adaptações, recriações e traduções famosas tiveram por autores personalidades ilustres como Tomaz Antonio Gonzaga (em redondilhas menores), Almeida Garret (em decassílabos), Lord Alfred Tennyson (em versos polimétricos), Jean Racine (em alexandrinos), William Carlos Williams (em versos livres), Lord Byron (em octossílabos), além de inúmeros outros. ${ }^{1}$

Em pleno século XXI, passados quase cem anos da Semana de Arte Moderna, há quem pergunte, não sem justa causa, se existe ainda algum sentido em traduzir poesia valendo-se de metro. Se sim, existe uma pergunta ainda mais difícil, que é a seguinte: qual o cabimento de traduzir poesia usando o metro original quando esse mesmo metro é completamente estranho à língua por meio da qual se traduzirá?

Para exemplificar o problema, gostaria de examinar a tradução desse poema de Safo feita por Jaa Torrano, visto que ele próprio é um exímio poeta do verso livre. Ainda que ele não costume comentar muito a respeito de seu método de tradução (do ponto de vista das escolhas estéticas) em seus trabalhos, em algumas conversas que tivemos, pareceu-me que, para ele, o verso (principalmente o livre, que, aliás, não é verdadeiramente livre pois) deve possuir uma unidade de sentido, de modo que seu término ou enjambement sejam significativos. A métrica, obviamente, torna-se obsoleta nessa concepção e o ritmo dos versos passa então a variar junto à sonoridade e de acordo com o sentido do texto, sem estar associado a algum esquema

1 Apresento, no apêndice, essas traduções e algumas outras. 
fixo. Vejamos, portanto, a tradução (ainda que eu bem saiba que ela é de todos conhecida): ${ }^{2}$

Parece-me par dos Deuses ser o homem que ante a ti senta-se e de perto te ouve a doce voz

e o riso desejoso. Sim isso me atordoa o coração no peito: tão logo te olho, nenhuma voz me vem

mas calada a língua se quebra, leve sob a pele um fogo me corre, com os olhos nada vejo, sobrezumbem os ouvidos,

frio suor me envolve, tremo toda tremor, mais verde que relva estou, pouco me parece faltar-me para a morte.

Mas tudo é ousável e sofrível...

Dentre todas, essa é a tradução em versos livres do poema de que mais gosto, pois dá conta de recriar a poeticidade do texto original, mantendo-se ao mesmo tempo bastante fiel ao que nele é dito.

Curiosamente, apesar dos versos da tradução serem livres e de seu ritmo ser arbitrário, seu melhor verso (a meu ver) segue de modo muito próximo o ritmo do original:

$-u-u-u-u-u$

mas calada a língua se quebra

$-u--\quad u \quad u-u$

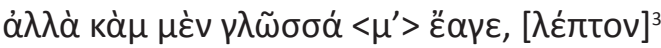
(2002). 
As duas únicas diferenças: i) a quarta posição do texto grego, um anceps, é preenchida por uma longa; ii) na tradução o professor preferiu

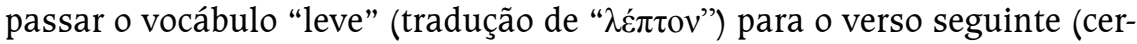
tamente porque dessa forma se enquadrava melhor na sua concepção de verso enquanto unidade de sentido). A semelhança rítmica apontada dá-se mediante uma óbvia analogia entre as sílabas tônicas e subtônicas no Português em relação às sílabas longas do Grego (e da mesma forma entre as sílabas átonas de um e as sílabas breves do outro). A passagem tem ainda o louvor de uma aliteração em /l/ ("calada", "língua") que se expande no verso seguinte ("leve", "pele").

Considerada (ainda que brevemente) a tradução em versos livres do Professor Torrano, chegamos a um ponto em que me parece justo dizer que existe algum mérito em traduzir (ao menos o poema em questão) usando o ritmo original, visto que o mais belo verso da tradução citada me parece ser justamente o que segue esse ritmo. Antes de examinarmos como poderia ficar uma tradução que optasse por esse viés, creio serem necessárias algumas observações a respeito da estrutura métrica e rítmica do poema original, cuja constituição dá a ilusão de ser bastante simples:

$$
\begin{aligned}
& -u-x-u u-u-x \\
& -u-x-u u-u-x \\
& -u-x-u u-u-x \\
& -u u--
\end{aligned}
$$

Apesar dessa aparente simplicidade, não há um consenso para a análise e para a nomenclatura de suas partes. Gentili e Lomiento (2007, p.149-50) a classificam como três hendecassílabos, originados a partir de trímetros coriâmbicos, seguidos por um adônio $(-\mathfrak{u} u--)$. West (1996, p.32-3), por sua vez, afirma que os dois primeiros versos são compostos por um metron jâmbico acefálico $(-\mathrm{u}-)$ seguido por um haguessicóreo $(\mathrm{x}-\mathrm{u}$ $\mathrm{u}-\mathrm{u}--)$. Ele diz ainda que o terceiro verso também pode ser visto da mesma forma, acrescido por um adônio, ou como um metron jâmbico acefálico seguido por um telesíleo $(\mathrm{x}-\mathrm{u} \mathrm{u}-\mathrm{u}-$ ) e um reiziano $(\mathrm{x}-\mathrm{u} u--)$. Nessa última configuração, a estrofe teria apenas três versos, o último mais longo que os dois primeiros (formato que pode ser visto em algumas edições).

Ainda que sejam hipóteses justas, parece-me, na verdade, que a estrofe se assemelha mais ao casamento do troqueu e do dáctilo, presente nas odes D/e de Píndaro e Baquílides, por exemplo, do que às complicadas 
soluções que vimos. Com efeito, pode-se considerar que seus versos sejam compostos por um metron trocaico $(-\mathrm{u}-\mathrm{x})$ seguido por um pé dactílico $(-\mathrm{u}$ $\mathrm{u})$ e outro metron trocaico $(-\mathfrak{u}-\mathrm{x})$. $\mathrm{O}$ quarto e último verso se adequa também perfeitamente a essa ordem, sendo então analisado como um dímetro dactílico catalético $(-\mathrm{u} u-\mathrm{x})$ :

$$
\begin{aligned}
& -u-x|-u|-u-x \mid \times 3 \\
& -u u|-x|
\end{aligned}
$$

Para fins de uma performance musical, parece-me possível que houvesse um prolongamento das longas dos troqueus (bem como uma padronização de todos as ocasiões de anceps para valerem como longas, mesmo quando breves), de modo a produzir o seguinte esquema, de compassos de 4 tempos: ${ }^{4}$

$$
\begin{aligned}
& \llcorner u|--|-u u \mid\llcorner u u \mid\llcorner u|--| \times 3 \\
& -u u|--|
\end{aligned}
$$

Para a tradução, segui uma forma métrica que pudesse reproduzir esse padrão, tomando a licença do último anceps poder ser suprimido, gerando um verso catalético com uma sílaba final (que numa enunciação rítmica ou musical deve ser) prolongada para 4 tempos (em vez de 2).

Tomei ainda uma última licença, semelhante à encontrada no verso original: a da quarta sílaba, na posição anceps, poder ser átona e ainda assim ter a duração de uma sílaba longa.

O resultado é um verso decassílabo (de final tanto masculino quanto feminino e) aparentemente mal feito, visto que não respeita as formas comumente aceitas em versificação portuguesa (com acento mandatório na sexta sílaba ou na quarta e na oitava, mas sim com acentos na terceira, na quinta e na oitava sílaba). Com esse padrão, realizei uma tradução do poema durante o mestrado. Mais tarde, criei uma pequena melodia, bastante simples, para ajudar a recitação do texto português na mesma duração do texto grego. É a seguinte: 

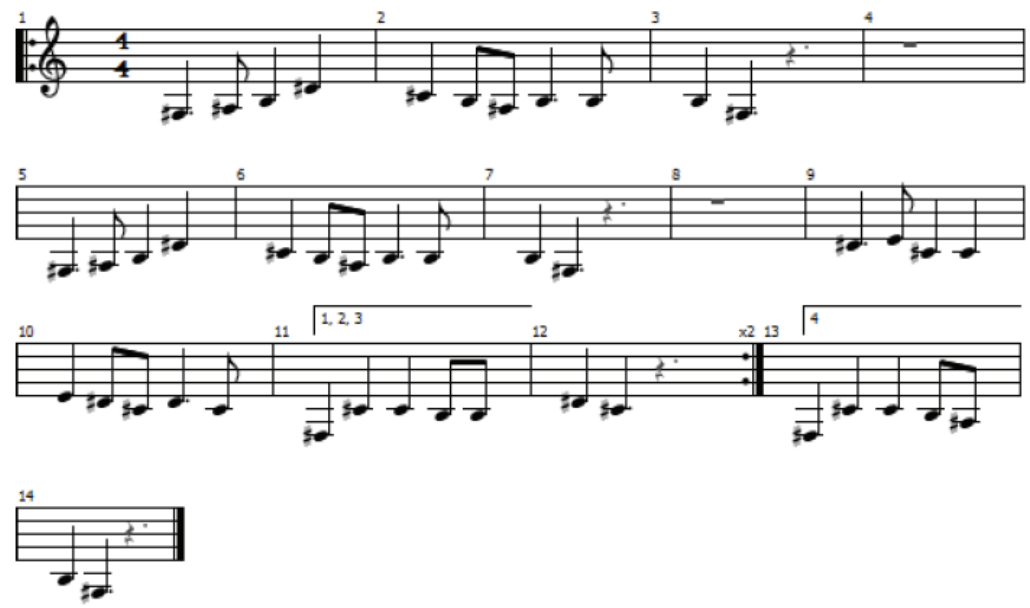

Seguindo essa notação musical, é possível recitar o texto original e a tradução em pé de igualdade..$^{5}$ Apresento ambos abaixo:

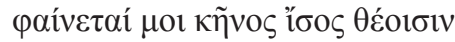

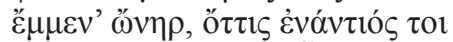

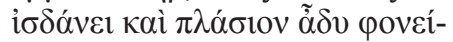

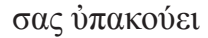

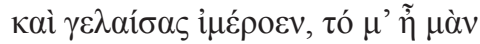

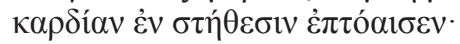

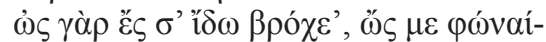

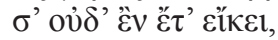

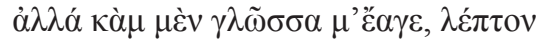

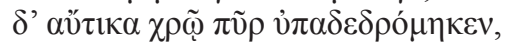

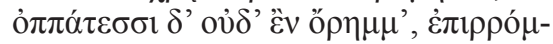

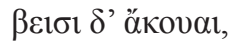

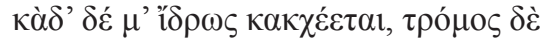

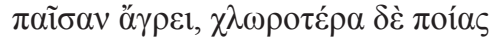

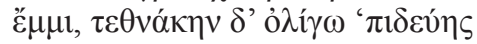

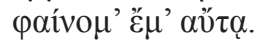
esse poema de Safo), a qual apresento no apêndice deste artigo, pode ser recitada da mesma forma, por seguir o mesmo padrão rítmico. 
Ele me parece ser par dos deuses, O homem que se senta perante ti

E se inclina perto pra ouvir tua doce Voz e teu riso

Pleno de desejo. Ah, isso, sim, Faz meu coração 'stremecer no peito. Pois tão logo vejo teu rosto, a voz eu Perco de todo.

Parte-se-me a língua. Um fogo leve Me percorre inteira por sob a pele. Com os olhos nada mais vejo. Zumbem Alto os ouvidos.

Verto-me em suor. Um tremor me toma Por completo. Mais do que a relva estou Verde e para a morte não falta muito É o que parece.

Essa solução tem a vantagem de apresentar o texto grego e o texto traduzido em plano de igualdade, numa relação complementar. As noções rítmicas e melódicas apresentadas são, obviamente, apenas hipóteses, as quais se validam mais no terreno da apreciação artística do texto (onde me parecem ter o potencial para algum sucesso) do que no campo da exegese.

Por outro lado, a desvantagem dessa solução é a de que ela carece da música para se fazer plena. Ainda que a tradução não seja desprezível se apenas lida, é pela música que ela atinge seu potencial máximo.

Por conta dessa dificuldade técnica, parece-me que as traduções em outros metros, de trato mais dócil na nossa língua, mantêm-se interessantes e belas, pois nem sempre se tem a oportunidade (ou o desejo) de ouvir a recitação rítmica ou musical de um poema.

Tal me parece ser o caso da recriação feita por Lord Byron, ainda que ele a tenha chamado de uma tradução de Catulo 51. De fato, ele segue o texto de Catulo inicialmente e de modo livre, mas por fim suprime sua última estrofe (em que o poeta latino saía do texto de Safo e discorria acerca do ócio) em prol de versos mais próximos aos da poetisa de Lesbos. Sua tradução é em versos octossílabos jâmbicos, com rimas emparelhadas, e mais digna de ser chamada de transcriação do que de tradução, devido à originalidade de seus versos: ${ }^{6}$ 
Equal to Jove, that youth must be, Greater than Jove, he seems to me, Who, free from Jealousy's alarms, Securely views thy matchless charms; That cheek, which ever dimpling glows, That mouth, from whence such music flows, To him, alike, are always known, Reserv'd for him, and him alone. Ah! Lesbia! though 'tis death to me, I cannot choose but look on thee; But, at the sight, my senses fly; I needs must gaze, but, gazing, die; Whilst trembling with a thousand fears, Parch'd to the throat, my tongue adheres, My pulse beats quick, my breath heaves short, My limbs deny their slight support; Cold dews my pallid face o'erspread, With deadly languor droops my head, My ears with tingling echoes ring, And life itself is on the wing; My eyes refuse the cheering light, Their orbs are veil'd in starless night; Such pangs my nature sinks beneath, And feels a temporary death.

Por gostar tanto dessa tradução de Byron (e por saber que a minha própria requer uma recitação rítmica ou musical para se fazer plenamente apreciável), resolvi fazer uma versão dessa recriação de Byron para a tradução de Catulo para o poema de Safo. Para tanto, usei versos dodecassílabos, visto que o Português carece de mais espaço para se desenvolver do que o Inglês. Ei-la:

Igual a Jove aquele jovem deve ser, Maior que Jove até me tende a parecer, Liberto, pois, da Inveja com os seus quebrantos, Seguramente vê teus ímpares encantos; Aquelas faces de covinhas luzidias, Aquela boca donde flui tal melodia Lhe são visões inteiramente conhecidas, Guardadas, para ele apenas permitidas. Ah, Lésbia!, mesmo sendo a morte para mim, Não posso me impedir de contemplar-te assim. 
Ao ver-te, entanto, perco os meus sentidos todos;

Preciso olhar, mas quando te olho eu logo morro.

Tremendo sob o jugo de temores mil,

A língua se me seca e quase me asfixio.

Meu pulso se acelera, o peito convulsiona;

Dos membros prontamente a força me abandona.

Um frio orvalho sobre o rosto me aparece;

Sob um langor funesto a fronte pronto desce.

Ruído reticente assalta-me os ouvidos;

A própria vida eu sinto quase ter perdido.

A luz gentil, a vista se recusa a vê-la,

Coberta numa noite sem nenhuma estrela.

A angústia se apresenta enfim como consorte

E por um tempo eu sinto ter chegado à morte.

Ainda que seja mais ou menos fiel ao texto, essa minha tradução para a tradução de Byron não traduz a originalidade que o poema de Byron apresenta em relação ao texto que imita. Por conta disso, fiz ainda uma recriação livre da tríade Safo-Catulo-Byron usando decassílabos e valendo-me da forma de um soneto inglês:

Parece-me um dos deuses elevados -

Ou mais que um deus se for possível sê-lo -

Esse homem que se senta do teu lado,

Tocando a tua pele e os teus cabelos,

E o dia inteiro escuta a tua doce

Voz e o teu riso pleno de desejo.

$\mathrm{Eu}$, mísero, queria que não fosse

Assim, pois só de ver-te eu já fraquejo,

Não resta um som no peito, a língua dorme,

Um fogo flui-me à veia e ao coração

E eu tremo e suo e sinto que, conforme

Tu chegas, toda a luz na escuridão

Se perde, as pernas cedem seu suporte

E já pareço estar próximo à morte.

Apesar dessas diferentes abordagens, com diferentes metros e diferentes extensões, parece-me que o efeito desses vários poemas (e suas traduções) não é muito distinto, de modo que concluo este texto dizendo que, seja em verso livre, em verso próximo ao ritmo original, empregando um metro distinto, fazendo uma tradução próxima ou uma recriação mais 
livre, o importante, a meu ver, é que a forma dialogue com o conteúdo de modo condizente com o ethos do poema, a fim de atingir uma beleza artística. Ao que me parece, o(s) mais alto(s) sentido(s) de um poema só pode(m) ser acessado(s) a partir da beleza artística que nele se desvela. $\mathrm{O}$ trabalho do tradutor é justamente o de auxiliar o leitor a atingir esse desvelamento da linguagem, a qual não é constituída apenas por um sentido racional, mas também por um sentido emocional, habitante dos sons e das cadências rítmicas. Desse modo, creio eu, todas as soluções de tradução poética são válidas desde que atinjam esse objetivo de encaminhar o leitor a essa dupla apreciação de forma e de sentido, a qual culmina no grau mais elevado da linguagem - o do sentido potencializado pela forma e da forma valorizada pelo sentido.

Apêndice: traduções, recriações e adaptações mencionadas

Ille mi par esse deo videtur, ille, si fas est, superare divos, qui sedens adversus identidem te spectat et audit

dulce ridentem, misero quod omnis eripit sensus mihi, nam simul te, Lesbia, aspexi, nihil est super mi vocis in ore,

lingua sed torpet, tenuis sub artus flamma demanat, sonitu suopte tintinant aures, gemina teguntur lumina nocte.

Otium, Catulle, tibi molestum est. Otio exultas nimiumque gestis. Otium et reges prius et beatas perdidit urbes.

(Catulo) $^{7}$ 
Ele me parece algum deus ao vê-lo Ele, se é possível, supera os deuses -, Que sentado em frente de ti de novo Te olha e te escuta

Rir tão doce, eu mísero perco todos Meus sentidos, pois, no momento mesmo Que te vejo, Lésbia, nenhuma voz me Resta no peito,

Já não sinto a língua; por sob os membros, Corre um fogo tênue; os ouvidos zumbem Mesmo no silêncio e na luz dos olhos Paira-me a noite.

O ócio faz tão mal para ti, Catulo.

No ócio exultas mais do que deverias.

o ócio no passado desfez cidades

Ricas e reis.

(Catulo, tradução minha) ${ }^{8}$

Feliz quem juncto ati por ti suspira, Que gosa do prazer de ouvir fallar-le E docemente ve surrir-te ás vezes. Igualar-lhe em ventura os deuses podem?

- Sinto chamma subtil de veia em veia Mal te vejo correr-me o corpo todo E nos doces transportes da minha alma.

Nem voz, nem lingua sei achar, que a exprimâo.

Nuvem confusa me ennoitece os olhos:

Não oiço, em doce languidez descaio.

Sem cor, sem respirar, quasi sem vida.

Tremendo em convulsões anceio, e morro.

\section{(Almeida Garret) ${ }^{9}$}

8 Como mencionado no texto, esta tradução segue o mesmo padrão rítmico de minha tradução musical para o phainetai moi.

9 Em Ramalho (1966, p.219). 
Mal vi o teu rosto,

O sangue gelou-se,

A língua prendeu-se,

Tremi, e mudou-se

Das faces a cor.

Marília, escuta

Um triste Pastor.

(Tomaz Antonio Gonzaga) $^{10}$

Je le vis, je rougis, je pâlis à sa vue;

Un trouble s'élèva dans mon âme éperdue;

Mes yeux ne voyaient plus, je ne pouvais parler;

Je sentis tout mon corps et transir et brûler.

$$
\text { (Jean Racine) }^{11}
$$

I watch thy grace; and in its place

My heart a charmed slumber keeps,

While I muse upon thy face;

And a languid fire creeps

Thro' my veins to all my frame,

Dissolvingly and slowly: soon

From thy rose-red lips my name

Floweth; and then, as in a swoon,

With dinning sound my ears are rife,

My tremulous tongue faltereth,

I lose my color, I lose my breath,

I drink the cup of a costly death,

Brimm'd with delirious draughts of warmest life.

I die with my delight, before

I hear what I would hear from thee;

(Lord Alfred Tennyson) $^{12}$

10 Marília de Dirceu, Lira IV, versos 8-14.

11 Phédre, Ato 1, Cena 3, versos 273-6.

12 Eleänore, versos 127-141. 
That man is peer of the gods, who

face to face sits listening

to your sweet speech and lovely

laughter.

It is this that rouses a tumult

in my breast. At mere sight of you

my voice falters, my tongue

is broken.

Straightway, a delicate fire runs in my limbs; my eyes

are blinded and my ears

thunder.

Sweat pours out: a trembling hunts

me down. I grow

paler than grass and lack little

of dying.

(William Carlos Williams) $^{13}$

13 Williams (2001: 348). 


\section{REFERÊNCIAS}

ANTUNES, C. Leonardo B. Métrica e Rítmica nas Odes Píticas de Píndaro. 343 f. Tese (Doutorado em Letras Clássicas) - Faculdade de Filosofia, Letras e Ciências Humanas, Universidade de São Paulo. São Paulo, 2012. Disponível em: <http://www.teses.usp.br/teses/disponiveis/8/8143/ tde-26062013-095555/publico/2012_CarlosLeonardoBonturimAntunes.pdf >. Acesso em 28/07/2014.

. Ritmo e sonoridade na poesia grega antiga: uma tradução comentada de 23 poemas. São Paulo: Humanitas, 2011.

BYRON, George Gordon (Lord). The Works of Lord Byron. Baudry: Paris, 1823.

CAMPBELL, David A. Greek Lyric I. Cambridge - London: Harvard University Press, 2002.

CATUlLUS. The Poems of Gaius Valerius Catullus. English Translation by: CORNISH, F. W. Cambridge - London: Cambridge University Press, 1921.

GENTILI, Bruno; LOMIENTO, Liana. Metrica e Ritmica. Città di Castello: Mondadori Università, 2007.

GILDERSLEEVE, Basil. Pindar: The Olympian and Pythian Odes. New York: American Book Company, 1885.

GONZAGA, Tomaz Antonio. Marília de Dirceu. 1. ed. São Paulo: Ediouro, 1997.

HESÍODO. Teogonia. Tradução e estudo de: TORRANO, J. São Paulo: Iluminuras, 2001.

OLIVA NETO, João Angelo. O livro de Catulo. Tradução, introdução e notas de: NETO, J. A. O. São Paulo: Edusp, 1996.

RACE, William H. Pindar I. Cambridge - London: Harvard University Press, 2002.

RACE, William H. Pindar II. Cambridge - London: Harvard University Press, 2002.

RACINE, Jean. Phédre. Paris: Universe de Lettres Bordas, 2003.

RAMALHO, Américo da Costa. Versões garretianas de Safo. In: Hvmanitas, vol.16-17. Instituto de Estudos Clássicos, FLUC: Coimbra, 1966.

TENNYSON, Alfred (Lord). The Early Poems. Echo Library: United Kingdom, 2006.

WEST, M. L. Greek Metre. Oxford: Clarendon Press, 1996.

WILLIAMS, William Carlos. The collected poems of William Carlos Williams. New York: New Direction Publishing Corporation, 2001.

Submetido em: 29/01/2014

Aceito em: 01/07/2014 